\title{
Urgências e emergências no cuidado: Narrativas de médicos residentes
}

Davisson Gonçalves Giaretta

Mônica Medeiros Kother Macedo

\section{RESUMO}

0 artigo retrata uma pesquisa qualitativa desenvolvida a partir de narrativas de médicos residentes cujas práticas profissionais ocorrem em contextos de urgência e emergência hospitalar. Tendo em vista as demandas e as exigências que constituem o processo formativo de um médico residente, bem como as especificidades inerentes ao exercício laboral nesse contexto, buscou-se identificar, compreender e problematizar os elementos presentes nessa singular experiência laboral. Participaram do estudo oito médicos residentes de diferentes instituições hospitalares do Sul do Brasil. Os achados do estudo foram trabalhados com o método de Análise Interpretativa proposto por Frederic Erickson e promoveram a formulação de três Asserções: Residência Médica: singulares trajetórias na busca pela excelência na formação; Exigências vs 'Sobrecarga': reflexões sobre os impasses da Residência Médica; e Desafios na construção da identidade médica: entre a necessária afetação e o risco da indiferença. Constatou-se que a busca pela residência médica orienta-se pela meta de alcançar a excelência do desempenho profissional, mas também contempla singulares demandas e exigências que podem tomar contornos de excesso provocando inegáveis e danosos efeitos à subjetividade do profissional médico.

Palavras-chave: residência médica; urgência; emergência; contexto hospitalar; formação médica.

\section{ABSTRACT}

\section{Urgency and emergency care: Narratives of resident doctors}

This paper describes a qualitative research developed from narratives of resident doctors whose professional practices take place in hospital urgency and emergency contexts. Considering the demands and requirements that make up the formative process of a resident doctor, as well as the specificities inherent to the work practice in this context, it was aimed to identify, to understand and to problematize the constitutive elements of such a singular labor experience. Eight resident doctors of different hospital institutions from the South of Brazil participated in this study. The findings of the study were analysed with the Interpretative Analysis method proposed by Frederic Erickson and have fostered the formulation of three assumptions: Medical Residency: singular trajectories in the search for excellence in the formation process; Requirements versus 'Overload': reflections over the impasse of Medical Residency and, Challenges in the construction of medical identity: between the necessary affectation and the risk of indifference. It has been verified that the search for medical residency is guided by the goal of achieving excellence in work performance, but it also contemplates unique demands and requirements that could lead to excess proportions, provoking undeniable and harmful effects to the subjectivity of the professional physician.

Keywords: Medical residency; Urgency; Emergency; Hospital context; Medical formation.

No campo laboral referente às práticas em saúde, mais especificamente, no contexto hospitalar, o profissional depara-se cotidiana e constantemente com a dor e o sofrimento do outro (Fagundes Netto \& Kernkraut, 2019; Moretto, 2019). No que tange especialmente ao contexto de urgência e emergência hospitalar, é exigida do profissional a prontidão no agir, visto que

\section{Sobre os autores}

D. G. G.

https://orcid.org/0000-00029192-369X

Pontifícia Universidade Católica do Rio Grande do Sul - Porto Alegre, RS

davissonggiaretta@gmail.com

M. M. K. M

https://orcid.org/0000-0001-

9347-8537

Universidade Federal do Rio

Grande do Sul - Porto Alegre, RS monicakothermacedo@gmail.com

\section{Direitos Autorais}

Este é um artigo de acesso aberto e pode ser reproduzido livremente, distribuído, transmitido ou modificado, por qualquer pessoa desde que usado sem fins comerciais. 0 trabalho é disponibilizado sob a licença Creative Commons CC-BY-NC.

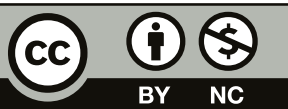




\section{INTERACÃO EM PSICOLOGIA}

rotineiramente se depara com o risco e o imprevisível. Ainda cabe considerar como especificidades desse local de trabalho as precárias condições laborais, superlotação e sobrecarga de trabalho (Rosado et al., 2015).

Esse cenário marcado pelo excesso e pela insalubridade gera inegáveis efeitos na subjetividade dos profissionais, especialmente nos médicos, que exercem seu fazer nesse âmbito, bem como demandam importantes desafios à capacitação profissional. Em muitas instituições hospitalares, encontram-se médicos que optaram por buscar seu aperfeiçoamento profissional por meio da Residência Médica. Como modalidade de especialização em nível de pós-graduação, a Residência caracteriza-se pelo treinamento em serviço, em regime de dedicação exclusiva (Decreto $n^{\circ} 80.281,1977,05$ setembro) . Cabe ressaltar que o documento primeiro o qual regulamenta a Residência Médica no país data de 1977 e segue, ainda, como principal balizador dessa prática, ou seja, mantêm-se em vigência suas bases e diretrizes.

Tendo em vista as vicissitudes demandadas na assistência à saúde e os elementos singulares inerentes à relação médico-paciente no campo hospitalar, torna-se relevante explorar e compreender a complexidade própria à experiência do médico residente. A partir da relevância atribuída às experiências profissionais e formativas de práticas em saúde, este artigo retrata uma pesquisa qualitativa, que objetivou explorar a experiência de Residência Médica e seus desdobramentos a partir de narrativas produzidas por médicos residentes em contexto de urgência e emergência hospitalar.

\section{MÉTODO}

Buscou-se no estudo, por meio de seu delineamento metodológico qualitativo, refletir sobre a singularidade das vivências dos participantes. A coleta dos dados ocorreu mediante o preenchimento de uma Ficha de Dados Pessoais e Sociodemográficos e da realização, com cada participante, de uma entrevista semidirigida. As entrevistas, com duração de, aproximadamente, uma hora, foram gravadas em áudio e transcritas na íntegra, assegurando a fidedignidade dos dados. Os trâmites éticos foram atendidos, sendo o estudo aprovado pelo Comitê de Ética em Pesquisa da universidade a qual se vincula a pesquisa. Participaram da pesquisa oito médicos residentes, os quais assinaram o Termo de Consentimento Livre e Esclarecido (TCLE) e cujas práticas profissionais, à época das entrevistas, estavam ocorrendo em contextos de urgência e emergência de instituições hospitalares. Os participantes foram selecionados por conveniência, por meio da técnica Bola de Neve (Turato, 2011), que consiste na identificação de alguns sujeitos, os quais indicarão outros possíveis participantes e, assim, sucessivamente. A fim
Davisson Gonçalves Giaretta e Mônica Medeiros Kother Macedo

de garantir o sigilo e o anonimato da identidade dos entrevistados e das instituições às quais pertencem, foram-lhes atribuídos nomes fictícios.

As entrevistas realizadas tiveram a seguinte questão disparadora: "Conte-me sobre tua experiência como médico residente no contexto de urgência e emergência nesta instituição". Buscou-se, a partir de então, investigar os seguintes eixos temáticos: percepções sobre a escolha da profissão e a transição do papel de aluno para o de profissional médico; significado do trabalho em Medicina; sentidos atribuídos às práticas de cuidado e de assistência à saúde pública; motivações para a escolha da Residência Médica; impasses, oportunidades e desafios enfrentados em contexto hospitalar de urgência e emergência; impactos emocionais decorrentes do trabalho e dos efeitos do cuidado exercido; recursos utilizados diante das demandas laborais; humanização da atenção e gestão em saúde.

Para a análise dos dados, utilizou-se o método Análise Interpretativa, proposto por Frederick Erickson (1997), o qual permite acompanhar o caminho percorrido pelo pesquisador no processo de perceber, dentre os vários elementos trazidos no material levantado, aqueles considerados proeminentes e que permitem formular Asserções sobre a temática pesquisada. É destinada ao pesquisador a tarefa de descobrir distintos estratos - tanto de universalidade quanto de particularidades - presentes no caso específico estudado. Destarte, busca-se identificar aspectos que são amplamente universais, que podem generalizar-se a outras situações similares; e os que são exclusivos do caso em questão. De acordo com o autor, a partir dessa etapa inicial de trabalho com os dados, chega-se a etapa de formulação das Asserções, decorrentes, portanto, das problematizações narradas pelos participantes. Após ocorre a revisão do corpus obtido nas entrevistas a fim de testar e retestar as Asserções construídas. É importante buscar nos dados as evidências que confirmem ou não a sustentação da afirmativa apresentada e, se necessário, levem à sua reformulação. Para Kude (1997), por meio da formulação das Asserções e de seu teste e reteste, busca-se por "ligações-chave" entre os dados obtidos que permitam interligar aspectos e características de um mesmo fenômeno. Trata-se de um "construto analítico que ata cordões entre esses itens, de forma que quando se puxa um cordão, haverá vários outros atados a ele" (Kude, 1997, p. 197). Por fim, realizou-se a redação da análise, constituída a partir de tópicos decorrentes das entrevistas e de seus comentários interpretativos (Erickson, 1997). Conforme Kude (1997), há três tipos de descrições essenciais nesta estrutura de texto: descrição particular, descrição geral e comentário interpretativo. A primeira consiste na essência do relatório de pesquisa, na medida em que apresenta e garante as asserções formuladas, sendo ilustrada pela vinheta narrativa. A descrição geral permite a generalização lógica dos achados, 
apresentando o quanto é típica ou atípica uma circunstância particular. Já o comentário interpretativo circunscreve as descrições de uma forma particular e geral.

\section{RESULTADOS E DISCUSSÃO}

A partir da análise dos dados obtidos foram elaboradas três Asserções, as quais serão abordadas a seguir. A caracterização dos participantes do estudo está descrita na Tabela 1.
"Tivemos um contato muito intenso e eu, apesar de gostar muito, foi ali que eu comecei a olhar e perceber o quanto que a gente desassiste o paciente na emergência".

Nas narrativas dos participantes predomina o desejo pela busca de aprimoramento e qualificação profissional, principalmente associada às práticas em urgência e emergência. Assim, a complementação e a qualificação da formação médica se dão como uma decorrência do objetivo do curso de Medicina, no sentido de buscar formar um profissional gene-

Tabela 1. Caracterização dos participantes

\begin{tabular}{cccccc}
\hline Participante* $^{\text {Idade }}$ & Sexo & Residência & Ano da Residência & Ano de formação em Medicina \\
\hline Augusta & 28 & F & Medicina de Emergência & R2 & 2014 \\
Rita & 32 & F & Medicina de Emergência & R2 & 2014 \\
Elizabeth & 33 & F & Gastroenterologia & R2 & 2010 \\
Giorgio & 36 & M & Medicina de Emergência & R2 & 2013 \\
Carlos & 25 & M & Medicina de Emergência & R2 & 2015 \\
Sophia & 30 & F & Medicina de Emergência & R3 & 2014 \\
Oswaldo & 27 & M & Pediatria & R1 & 2016 \\
Alice & 31 & F & Emergência Pediátrica & & 2013 \\
\hline
\end{tabular}

*Nomes fictícios

\section{PRIMEIRA ASSERCÃO "RESIDÊNCIA MÉDICA: SINGULARES TRAJETÓRIAS NA BUSCA PELA EXCELÊNCIA NA FORMAÇÃO"}

0 curso de Medicina objetiva proporcionar uma formação geral, humanista, crítica, reflexiva e ética que contemple, no currículo de graduação, diferentes níveis de atenção à saúde ( Resolução nº 03/2014, 2014, 20 junho). Espera-se, na Residência Médica, a obtenção de aprimoramento após a graduação em Medicina (Martins, 2010). Constatou-se que os participantes do estudo compartilhavam dessa expectativa, na medida em que buscaram na Residência a excelência na formação para além da graduação em Medicina. Rita constata que o profissional, durante a graduação, muitas vezes, não vivencia a rotina de um médico em unidade de emergência, não estando apto para o atendimento de casos graves e de alta complexidade.

"Ninguém sai preparado da faculdade para atender numa sala vermelha, por exemplo. (...) o recém-formado não está preparado para isso, com certeza não está!"

Sophia revela ter tido maior contato com pacientes em situações de urgência e emergência durante sua graduação em Medicina, o que a motivou a optar pela Residência em Medicina de Emergência. ralista. Tal complementação ocorre, prioritariamente, por meio da realização da Residência Médica, definida pelo Decreto $n^{\circ}$ 80.281 de 5 de setembro de 1977 , como uma

modalidade do ensino de pós-graduação destinada a médicos, sob a forma de curso de especialização, caracterizada por treinamento em serviço em regime de dedicação exclusiva, funcionando em Instituições de saúde, universitárias ou não, sob a orientação de profissionais médicos de elevada qualificação ética e profissional (p. 1).

A Residência, pioneira na área médica como modalidade de ensino em serviço, é tida como "padrão-ouro" na especialização e qualificação médica, especialmente do profissional recém-formado (Decreto $n^{\circ} 80.281,1977,05$ setembro), sendo, então, consagrada como a melhor forma de inserção do médico na vida profissional. No que diz respeito ao treinamento do médico residente em contextos institucionais de urgência e emergência, a Resolução do Conselho Nacional de Residência Médica (CNRM) nº 02/2006 (2006, 17 maio) estabelece que diversas especialidades médicas, principalmente as de acesso direto, devem incluir o treinamento do residente em contextos de urgência e emergência durante o curso. A especificidade da prática laboral é citada por Alice: 


\section{MLE INTERACÃO EM L* PSICOLOGIA}

"Normalmente tu está sempre com casos mais complexos ou possivelmente complexos. (...) É diferente de tu estares no andar".

Embora o médico residente seja um profissional formado, na residência ele se depara com a dualidade de ser estudante e, ao mesmo tempo, trabalhador (Martins, 2010). Ou seja, a Residência é um intenso aprendizado que se dá, em sua maior parte, por meio do treinamento na experiência prática supervisionada. Para tal, existe uma preceptoria exercida por um médico mais experiente com elevada qualificação ética e profissional (Decreto n 80.281, 1977, 05 setembro). Oswaldo reconhece a importância do respaldo da preceptoria, atribuindo-Ihe a experiência de rico aprendizado e, também, de autonomia:

“(...) a lógica é sempre ter um respaldo, ter sempre uma pessoa mais experiente nos dando orientação, mas é a gente que está ali lidando direto com o paciente, lidando com o familiar, com o resto da equipe".

Sant'Ana e Pereira (2016), ao analisarem a atividade da preceptoria na perspectiva de médicos preceptores em um serviço de urgência e emergência hospitalar, constataram positivas influências para o discente. Dentre essas influências, salientam os autores, estão o valor dado ao conhecimento prático da Medicina no local de trabalho, além dos aspectos humano e ético na formação de profissionais qualificados. Sabe-se, porém, que a unidade de emergência hospitalar é, muitas vezes, também um local que absorve médicos recém-formados na modalidade de plantões. Cabe destacar que esses plantões não estão vinculados à Residência, resultando, muitas vezes, em grande rotatividade de profıssionais e de instituições.

“(...) às vezes o paciente pode estar numa situação com um
médico muito bom, que vai salvar a vida dele, vai resolver o
problema dele, ao passo que pode se encontrar com uma
pessoa que está ali, está fazendo o trabalho dela, mas não
tem conhecimento que precisa para salvar aquele doente.
(...) Numa emergência tem muita gente que não tem a com-
petência técnica para atuar ali. (...) Médico brasileiro traba-
lha com a emergência como forma de ganhar dinheiro. A
gente termina a faculdade e vai para a emergência trabalhar,
ganhar dinheiro" (Sophia).

Tendo em vista o expressivo número de trabalhadores já atuantes nos serviços de urgência e emergência, a Portaria do Ministério da Saúde $n^{\circ} 2.048$ ( Portaria GM/MS n².048, 2002, 05 novembro) prevê a capacitação e a educação continuada desses profissionais. Nesse sentido, a Resolução do CFM n² 2.077/14 ( 2014) torna obrigatória a qualificação dos médicos para o exercício laboral em Serviços Hospitalares de Urgência e Emergência. No entanto, o médico, muitas vezes, inserido no setor de urgência e emergência, é um profissio-
Davisson Gonçalves Giaretta e Mônica Medeiros Kother Macedo

nal recentemente formado, inexperiente, com dúvidas e inseguranças, dando-se sua inserção nesses serviços de forma precoce (Pereira Jr. et al., 2015; Purim et al. , 2016). Constata-se que, frequentemente, ocorre um despreparo técnico do profissional para atuar em diferentes situações de urgência e emergência (Pereira Jr. et al., 2015), revelando descuido não somente com o paciente, mas, também, para com o profissional em início de carreira.

"Então, inicialmente, onde a gente mais consegue emprego, ou fazer 'bico', é nessa área de urgência e emergência" (Oswaldo)

Oswaldo nomeia como "bico" o que é considerado um "segundo" emprego, com menor importância e com intuito, na maioria das vezes, de complementação da renda do profissional. No Brasil, a emergência é uma área na qual, histórica e culturalmente, médicos trabalham na modalidade de "bico", não investindo efetivamente em seu aprimoramento técnico.

"Quando surgiu essa especialidade, essa coisa de não ter ninguém ali [na emergência], tu vai pegar lugares, plantões no interior, em outros lugares, cada turno é alguém diferente, tu está fazendo 'bico', como o pessoal chama aqui. E ninguém resolve nada, não tem nenhuma referência (...) porque tem sempre que estar ali só para fazer um extra, que quer ir lá só para fazer o necessário, não se incomodar e tchau." (Carlos).

No reconhecimento do risco de que o setor de emergência e a exigência de singular qualificação profissional por ele demandada passem despercebidos, os participantes enfatizam a relevância do reconhecimento da Medicina de Emergência como especialidade médica ( Resolução nº 02/2006, 2006, 17 maio) . O risco decorrente do descuido relacionado ao exercício profissional em contexto de urgência e emergência era também evidenciado, até o ano de 2015, pela escassa oferta e pelo não reconhecimento dessa modalidade de Residência, existente, até então, em apenas duas instituições hospitalares do Brasil. Esse dado, somado ao fato de a emergência ser a porta de entrada do hospital e, muitas vezes, do próprio sistema de saúde, bem como não ser o local de preferência de investimentos por parte do Estado, revela a desvalorização desse setor e, consequentemente, dos profissionais que ali trabalham. Por outro lado, o reconhecimento do título de especialista em Medicina de Emergência e das duas Residências já existentes bem como a criação de novos programas de Residência na área são elementos que viabilizam a formação de médicos emergencistas de carreira, valorizando e capacitando esses profissionais para o trabalho em contexto de urgência e emergência.

"Acho que a gente está com uma geração de residentes agora que está tendo que encarar um trabalho horrível de mostrar para todo mundo que nós somos especialistas e que 


\section{H. INTERACÃO EM PSICOLOGIA}

a gente está aqui porque a gente gosta, e a gente vai fazer isso a vida inteira" (Sophia).

A conquista da denominação de especialista reflete o árduo trabalho de busca por uma identidade profissional como médico emergencista. Ao buscar a excelência e a especialização médica por meio da Residência, os profissionais entrevistados também acabaram deparando-se com desafios e impasses. Tais exigências adquirem, muitas vezes, contornos e proporções experienciadas como excesso.

\section{SEGUNDA ASSERCÃO “EXIGÊNCIAS VS 'SOBRECARGA': REFLEXÕES SOBRE OS IMPASSES DA RESIDÊNCIA MÉDICA"}

Nesta Asserção, lança-se luz, a partir das narrativas dos residentes, aos elementos denominados como "sobrecarga" no contraponto ao que descrevem como "exigências" presentes no percurso da Residência. A "sobrecarga" toma contornos de excesso, de algo que ultrapassa em intensidade o esperado, apresentando-se com frequência na rotina do profissional e produzindo, assim, importantes e inegáveis efeitos nos sujeitos trabalhadores. Referem a existência de exigências que contribuem e potencializam a desejada qualificação, mas identificam a sobrecarga como o que restringe e impede ritmos e processos de genuína aprendizagem e formação. Nas narrativas está o reconhecimento atribuído às experiências que promovem o exercício de raciocínio clínico e diagnóstico precisos, mesmo que sob o ritmo intenso e acelerado da urgência e da emergência. Carlos reconhece que o treinamento na Residência deve contemplar o manejo de casos sob uma condição de prontidão.

"(...) tu vai estar em uma situação que vai ter que fazer várias coisas e sob muito estresse, então pressionar e criar um pouco mais de estresse é necessário para tu te acostumar com a situação. (...) Te preparar para trabalhar nessas situações com mais estresse faz parte. Mas tem que se buscar esse equilíbrio, para também não ser demais".

Salienta-se a necessidade de "equilíbrio" mencionada pelo participante que, muitas vezes, não é a realidade encontrada nos programas de Residência Médica. Nesse sentido, os participantes, em consonância com os achados de Fagundes Netto e Kernkraut (2019), aludem a aspectos geradores de intenso estresse e sofrimento que poderiam ser evitados ou manejados, entretanto não o são. Esses são os elementos explorados nesta Asserção sob a denominação de "sobrecarga". Os "excessos" referidos incluem a extenuante demanda de trabalho e a exagerada carga horária a ser cumprida, bem como o desamparo experimentado. Essas condições geram acentuado sofrimento psíquico, conforme relata Elizabeth:

"Esse sofrimento que tu vai passando de sobrecarga na residência. Porque é muita sobrecarga, muita sobrecarga.
Davisson Gonçalves Giaretta e Mônica Medeiros Kother Macedo

(...) Às vezes não ter tempo de almoçar. (...) Tu trabalha que nem um condenado. (...) Tu esquece de fazer xixi, tu esquece de comer. Às vezes é muito ruim. É desumano! (...) Tu trabalha como mão de obra demais, muitos dias tu passa mais de doze horas por dia no hospital. Às vezes tu vira trinta e seis horas".

Surgem como contraponto à exaustão decorrente da Residência o desejo, a motivação e a determinação do médico para superar a "sobrecarga" e a inflexibilidade do curso. Identifica-se, portanto, importante risco de tornar equivalente o atendimento à "sobrecarga" ao desejo de excelência na prática em Medicina. É importante constatar a inviabilidade de que, mediante essas condições, ocorra um trabalho de qualidade sustentado na satisfação laboral. O ritmo cotidiano de excesso e o dano à aprendizagem e capacitação é descrito com precisão por Sophia:

"A gente tinha a sensação de que nunca tinha tempo para estudar. E não tinha mesmo, o tempo que eu tinha livre eu queria dormir. (...) Você tem a sensação de que tudo está acontecendo mais rápido do que você pode acompanhar".

Embora a Lei $n^{\circ}$ 6.932/1981 ( 1981, 07 julho) estabeleça que a carga horária da Residência Médica não deva ultrapassar 60 horas semanais, nelas incluídas um máximo de 24 horas de plantão, percebeu-se, nos dados obtidos neste estudo, que os programas de Residência Médica diferem entre si quanto à carga horária a ser cumprida pelo médico residente. Logo, o enfrentamento com a "sobrecarga" no cenário de Residência é uma situação frequente e comum aos médicos residentes entrevistados. Frente ao cenário marcado pela "sobrecarga" e sua possível naturalização pelos profissionais, alerta-se para o risco à saúde dos médicos residentes frente à instalação de processos que vão na contramão de procedimentos que resultem em genuína qualificação profissional.

“(...) na faculdade tu ainda não tem essa ideia. (...) sempre alguém é responsável por aquilo. Na residência não... Tu que é o responsável. O paciente é teu" (Rita).

Nesse sentido, observa-se o incentivo à autonomia profissional quando amparado por uma preceptoria que exerce efetivamente sua função. No entanto, frente a um exercício de preceptoria que falha ao cumprir sua função, pode-se confundir a atribuição de autonomia com negligência e descuido para com o médico residente e com seu processo de busca por qualificação. Nessa direção, destacou-se, nos dados obtidos, outra consequência nefasta para o residente, relativa a situações de assédio moral. Elizabeth narra o assédio moral sofrido em sua Residência, além de testemunhar o abuso psicológico sofrido por colegas de outras especialidades médicas.

"Sofri nos primeiros três meses, eu ia chorando todos os dias para casa, pensando em desistir pela coisa de humilhação 


\section{4.' INTERACÃO EM PSICOLOGIA}

por parte de professor, de maus tratos mesmo, não era uma coisa de apanhar fisicamente, mas mentalmente era demais. Então, existe abuso moral muito grande por parte dos preceptores, muito grande, muito grande mesmo. (...) Graças a Deus é a minoria, mas existe muito e é extremamente abusivo (...) é uma coisa que se repete há muitos anos".

Elizabeth destaca o caráter repetitivo desse assédio, bem como os deletérios efeitos sentidos por ela. Segundo Marques et al. (2012), assédio moral consiste em uma

deliberada degradação das condições de trabalho por meio do estabelecimento de comunicações não éticas (abusivas) que se caracterizam pela repetição, durante longo tempo, de um comportamento hostil (p. 403).

Volz et al. (2017), em estudo piloto, constataram presença de comportamentos de violência horizontal (assédio moral e ameaças verbais ou físicas) em profissionais da saúde, inclusive residentes, em serviço de emergência. Diante do cenário de excessos, evidencia-se a deficiência no cuidado destinado a esses profissionais. Nesse sentido, pesquisas (Abdulghani et al. , 2015; Çalişkan Tür et al., 2016; Ilić et al., 2017) constatam que elevadas exigências laborais, atribuição de demasiada responsabilidade, insegurança no trabalho e elevados níveis de estresse ocupacional interferem significativamente na atividade laboral de médicos emergencistas. Considerando que os serviços hospitalares de urgência e emergência estão inseridos no Sistema de Saúde brasileiro e são influenciados por ele, Augusta narra as dificuldades encontradas tendo em vista a realidade do sistema de saúde:

"As coisas estão difíceis, porque o sistema de saúde não valoriza a emergência, não há investimento em emergência. (...) a emergência é só a porta de entrada. Só. E acaba. (...) E aí a gente acaba sendo assim, meio sucateado, e não é só aqui, eu estou dizendo no geral. (...) Escassez de tudo, de mão de obra qualificada, de equipe qualificada. (...) É uma dificuldade imensa para nós, que quando a gente entra, tem que entrar com uma força muito grande, vou encarar porque é uma coisa difícil de mudar, a curto prazo não".

A precariedade do Sistema de Saúde denota um descuido em relação a seus usuários que, por sua vez, tem inegáveis consequências àqueles que exercem o cuidado, conforme ilustra a narrativa de Rita.

"É uma situação extrema que, às vezes, as pessoas [usuários do Sistema de Saúde] não conseguem lidar e acabam descarregando em quem passa ali, que muitas vezes é a gente. (...) Não é pessoal contigo, ela só está descarregando a revolta dela com o sistema que não funciona muitas vezes".

As narrativas dos participantes revelam, também, a existência de parcos recursos pessoais frente à "sobrecarga" com a qual se deparam. A vulnerabilidade identificada por eles pro-
Davisson Gonçalves Giaretta e Mônica Medeiros Kother Macedo

voca importantes danos à saúde, por exemplo, no uso excessivo de álcool e de automedicação.

"A nossa válvula de escape é nas [dia da semana], no pós-aula, beber e dar risada entre o grupo. (...) Quando tu começa a ter uma válvula de escape de ir para um bar é ruim". (Giorgio).

"Automedicação tem, mas mais em relação a coisas específicas, tipo ansiolítico, remédio para dormir. Coisas pontuais, assim, que eu vejo o pessoal usar". (Carlos).

0 participante Giorgio alude a um descuido atribuído à instituição, pois considera que inexistem alternativas institucionais para dar conta dessa "sobrecarga" própria do programa de Residência. O tema da automedicação por parte de médicos residentes é bastante controverso, uma vez que o dano decorrente de tal prática pode ser minimizado, como se constata na fala de Carlos. Roberts e Kim (2015), em seu estudo, observaram que o cuidado informal via automedicação consistia em uma prática comum entre os 155 médicos residentes pesquisados.

Ainda sobre a prática da Residência Médica, constata-se um relevante impasse entre o que é prescrito em sua regulamentação e a efetiva vivência encontrada nas narrativas dos participantes. Evidencia-se, dessa forma, uma espécie de efeito "cascata" frente a qual o descuido do Sistema de Saúde em relação aos usuários (nível macro) se reproduz nas práticas institucionais de exigência aos médicos residentes (nível micro). Inevitavelmente, a rotina dos serviços hospitalares de urgência e emergência passa a sofrer importantes efeitos decorrentes da precariedade própria ao Sistema de Saúde brasileiro. Percebe-se, portanto, uma forte influência decorrente de complexa condição social que compreende o campo do Sistema de Saúde, no qual estão inseridos os serviços hospitalares de urgência e emergência. Os dados obtidos evidenciam que a precária realidade dessa condição social é percebida, mas, ao mesmo tempo, alterada (desmentida) no que diz respeito à prática do médico residente.

"Para ti ver como o sistema é uma 'naba'. Como os caras [médicos preceptores da instituição] são concursados, o que eles vão fazer para tapar o furo e não deixar de atender o povo? (...) Aí o residente fica tocando serviço, não tem preceptor, às vezes. (...) Então, hoje, o residente ele é usado como uma forma de quebrar... de suplantar um sistema quebrado". (Giorgio).

"Em geral, no Brasil, residente, ele é mão de obra barata para tapar furo, querendo ou não". (Carlos).

As narrativas de Giorgio e de Carlos denunciam tanto o desamparo, no que concerne à falta de efetividade da função de preceptoria na "sobrecarga" vivenciada na Residência, quanto o fato de o trabalho do médico residente alterar/desmentir as deficiências na assistência à saúde. Identifica-se evidente 


\section{H. INTERACÃO EM PSICOLOGIA}

alteração e descuido que ocorrem quando o médico residente é convocado a desmentir, com sua presença, a ausência daquele que ali deveria estar.

"Ser residente não é trabalhar além daquelas horas que a gente tem que trabalhar, que não é ser a peça chave da emergência, que a emergência tem que saber funcionar sem a gente e também porque a gente só não aprende na prática, a gente tem que ter tempo para estudar, a gente tem que ter tempo para descansar, tempo para dormir". (Sophia).

Logo, se a "sobrecarga" impera, questiona-se como poderá se dar efetivamente o processo de qualificação profissional do médico residente. Para tanto, destaca-se, a partir da constatação da lacuna entre o prescrito e o efetivo, a importância de lançar luz sobre os danosos efeitos subjetivos decorrentes dessa condição laboral.

\section{TERCEIRA ASSERÇÃO “DESAFIOS NA CONSTRUÇÃO DA IDENTIDADE MÉDICA: ENTRE A NECESSÁRIA AFÉTAÇĀO E 0 RISCO DA INDIFERENÇA"}

Atentar às repercussões da "sobrecarga" na subjetividade dos entrevistados encontra-se em consonância com o primeiro princípio norteador descrito na Política Nacional de Humanização, o qual valoriza a dimensão subjetiva em todas as práticas de atenção e gestão (HumanizaSUS, 2004). Nesta Asserção exploram-se as narrativas dos participantes no que concerne ao desafio da condição de afetação na prática profissional, bem como aos riscos de vivências que fomentem práticas marcadas pelo predomínio da indiferença. Neste estudo, entende-se indiferença como uma postura que resulta tanto na impossibilidade de um cuidado sensível e afetivo voltado a si mesmo como, também, à demanda do outro. Acredita-se que uma prática marcada pela experiência predominantemente sensível e afetiva promove condições à mutualidade do cuidado. Na narrativa de Giorgio, observa-se ser imprescindível a sensibilidade e a afetação por parte do médico residente em sua prática.

"Ser frio diante de uma situação para que você consiga ajudar o paciente é diferente de você ser insensível à situação. (...) Ser frio numa emergência é imprescindível, eu diria, porque se você começar a pensar: 'Ah, tadinho, vai sentir dor, eu não vou fazer isso', o cara morre! (...) Então frieza e determinação é diferente de insensibilidade. (...) Não tem como não se sensibilizar com a dor do outro. (...) E essa dor que eu falo é uma dor não só física, uma dor emocional".

Aredes e Modesto (2016) constataram, a partir de um estudo qualitativo sobre a prática médica em um serviço de urgência e emergência hospitalar, que a atuação desse profissional é também mediada pela sensibilidade e afetividade, mesmo que de forma velada, pela estrutura biomédica. Conforme narrativas dos participantes do estudo, o não
Davisson Gonçalves Giaretta e Mônica Medeiros Kother Macedo

reconhecimento dos efeitos dessas situações na subjetividade do médico, principalmente nas situações de quadros clínicos terminais ou irreversíveis, pode vir a fomentar práticas marcadas pela indiferença a si e ao outro. É importante que o profissional identifique a diferença entre "curar" e "cuidar". Por vezes, a tarefa do médico não terá por finalidade a cura, como por exemplo, em casos de pacientes que demandam cuidados paliativos. No entanto, a possibilidade de exercer um cuidado sensível pode promover melhores condições no exercício da Medicina. Nessa direção, Sophia alerta para o fato de que o médico nem sempre salva vidas, mas sim proporciona o cuidado necessário àquele paciente no atendimento de suas singulares demandas.

"A gente lida com muita gravidade. (...) Morte, morte, morte quase todo dia. (...) A gente aprende que a gente não pode salvar todo mundo, que a gente não está ali para isso. $A$ gente está ali para oferecer o melhor que o paciente precisa naquele momento. (...) Saber lidar com isso também.(...) $E$ às vezes a gente se perde nisso".

É evidente o desafio que se apresenta no processo de construção da identidade médica. Por um lado, persiste uma equivalência entre um exercício de excelência da Medicina e uma prática marcada pela indiferença frente aos afetos e sentimentos experimentados pelo médico. Por outro lado, impõe-se a noção de que o exercício de uma Medicina de excelência precisa estar ancorado em um atendimento humanizado. Tomando a definição de atendimento humanizado como aquele que reconhece a relação entre duas pessoas (médico-paciente), pode-se considerar que é imprescindível, para efetivar-se tal condição, a afetação do profissional.

Cabe problematizar, portanto, o quanto a necessária afetação não deve ser confundida com limitações à capacidade técnica. Quando um profissional consegue reconhecer os limites em seu anseio de curar, porque identifica que, para aquele paciente, naquela condição, tal motivação não é pertinente, nada o impede de oferecer sua competência de cuidar. Oswaldo, ao contar sobre sua prática, denota empatia ao "sentir com" o outro, mas revela, também, a necessidade de se recompor rapidamente para dar continuidade ao seu trabalho.

"Quando se perde uma vida ou quando se vê que o paciente está mal, nós também acabamos ficando mal, só que o problema é que daqui a pouco, daqui a 10, 15 minutos, a gente já tem que atender um outro paciente que também vai precisar de cuidados. Então, muitas vezes, a gente acaba deixando... tendo, obrigatoriamente, que deixar de lado o sentimento para ser muito racional nessas horas. (...).

Para o médico exercer sua prática profissional com efetiva excelência, cabe a ele reconhecer em si o impacto emocional de seu trabalho. Para Rios (2009), "saber administrar-se bem e com bom senso é a arte da relação interpessoal e do cuidado 


\section{MLE INTERACÃO EM PSICOLOGIA}

consigo mesmo" (p. 52). 0 risco, portanto, apresenta-se quando não é permitido ao médico reconhecer em si o impacto emocional de suas práticas, imperando a necessidade de continuar trabalhando às custas dessa não percepção. Quando o médico é impedido de perceber e reconhecer sua afetação com as situações dos pacientes, acaba por estimular uma prática marcada pela indiferença também em relação a si mesmo.

"Situações em emergência (...) a gente acaba conhecendo muito os perfis dos pacientes e acaba tendo um... não um feeling, eu digo, que não é só a questão de sentir, mas é de conhecer, de juntar fatores e entender qual paciente vai ser um pouco pior que o outro. Então a gente acaba ficando preparado para algumas situações, mas tem situações que é muito difícil a gente se preparar, que é, no meu caso, o que é difícil é doença grave em criança e adolescente". (Augusta).

A imprevisibilidade do trabalho do médico no contexto de urgência e emergência faz com que somente o conhecimento técnico não seja suficiente. Augusta, ao referir o sentimento como um dos fatores importantes norteadores de sua prática, também identifica o que lhe exigirá maior demanda emocional. As situações inesperadas aludem à imprevisibilidade do caso a ser atendido, sendo a capacidade de prestar atenção em si mesma que lhe possibilita seguir trabalhando com o inesperado. Miranda et al. (2012) constataram, a partir de estudo qualitativo, que as situações de difícil manejo relatadas por médicos estão associadas àquelas que estão para além dos aspectos teóricos e científicos, não podendo ser solucionadas apenas por meio desse saber. A partir dos relatos, identificou-se o reconhecimento de que o trabalho médico possa ser exercido com afetação e sem prejuízo à competência técnica. 0 essencial reconhecimento do outro no campo alteritário surge como fator que possibilita ao médico estabelecer relações permeadas pela condição de se afetar e se distanciar do risco de uma prática regida pela indiferença. Ressalta-se a imprescindível sensibilidade do médico no exercício de seu trabalho, podendo contrapor-se a uma forma comum de expressão da indiferença - a arrogância -, conforme descreve Carlos:

"No plantão não tem tanto uma certa altivez como nas outras áreas médicas, por exemplo, tem mais um pouco, a arrogância. Não que não tenha [na emergência], mas menos, comparativamente".

$O$ risco da indiferença pode ser compreendido sob a perspectiva na qual o profissional médico é visto e tratado como "super-herói", prevalecendo, assim, o estímulo ao não reconhecimento ou ao escamoteamento de suas limitações e fragilidades como ser humano. A figura mítica e onipotente do super-herói parece dar conta de um profissional invulnerável, que não é abalado, tampouco afetado por nada. Porém, corre-se o risco, na prevalência de tal distorção, do surgimento de importante descuido aos aspectos subjetivos do médico.

\section{Davisson Gonçalves Giaretta e Mônica Medeiros Kother Macedo}

"Parece que tu é super homem, que vai viver para sempre, essa é a impressão que eu tinha. Que nunca vai acontecer nada comigo". (Rita).

Carlos alude à desvalorização da subjetividade do profissional no campo da Medicina:

"Mesmo entre colegas e com a equipe acho que é uma coisa muito subvalorizada. (...) Subestimada na medicina, no ensino da medicina."

Nessa direção, constata-se que a formação médica ainda privilegia o modelo biomédico, predominantemente tecnicista, racional e individualizado, com tentativas, por vezes isoladas, de exercício da crítica, criatividade e sensibilidade (Goulart \& Chiari, 2010; Rios, 2016). Esse modelo, segundo os autores, é herança da ciência dura, pragmática e positivista que, com o passar do tempo, distanciou-se dos conhecimentos do campo das humanidades. Nesse modelo formativo, segundo Rios (2016), corre-se o risco de o paciente, e também o médico, perder seu lugar de sujeito, sendo ambos tratados como partes de uma engrenagem. As narrativas dos participantes do estudo revelaram, também, a inexistência de espaços formais na Residência que tenham o efetivo intuito de reconhecer, abordar e refletir sobre os aspectos subjetivos do residente.

"A gente acaba tendo essa parte mais emocional quando fica fora do ambiente de assistência. Daqui a pouco num intervalo quando a gente vai almoçar com os colegas, acaba discutindo os casos e comentando. (...) Se deixa de lado um pouco mais a ciência e vira mais emoção. (...) Não tem um momento oficial que a gente possa discutir". (Oswaldo).

A constatação da inegável influência exercida pelos modelos no processo formativo conduz à reflexão sobre os impactos na formação da identidade profissional do médico. Essas influências decorrem de um cenário, na maioria das vezes, marcado pelo estímulo ao predomínio da "sobrecarga" na exigência de tarefas e pela desconsideração ao risco de indiferença ao outro e a si mesmo. Carlos faz menção à existência de um "currículo oculto", ou seja, modalidades de aprendizado implícitas a partir dos modelos profissionais ofertados no processo de formação do médico.

"O currículo não é só o que está escrito, a parte técnica, é também aprender com as posturas. Tu aprende muito com os chefes, a maneira de se portar com o paciente, de se portar com o colega, a maneira de se portar com o familiar."

Uma vez que os médicos preceptores são tomados como modelos profissionais, é evidente a relevância da preceptoria na formação da identidade profissional do médico residente. Nesse sentido, Moretto (2019) enfatiza a prática de ações de cuidado baseadas no acolhimento e na escuta, para além dos protocolos, a fim de fornecer subsídios para a formação de profissionais da saúde capazes de acolher o singular 


\section{MLE INTERACÃO EM LTPSICOLOGIA}

sofrimento. Para tanto, na formação médica, faz-se imprescindível o efetivo acolhimento e a genuína escuta do médico residente. Formação essa que deve contemplar não somente a competência técnica, mas, também, deve abranger, com igual importância, os aspectos subjetivos do médico em formação, a fim de fomentar práticas que aliem competência técnica e sensibilidade.

\section{CONSIDERAÇÕES FINAIS}

0 estudo realizado permitiu abordar a complexidade de demandas e exigências que constituem o processo formativo de um médico residente, bem como evidenciar especificidades inerentes ao exercício laboral no contexto de urgência e emergência. Os dados obtidos permitem reconhecer que uma prática médica regida pela condição de cuidado integral ao outro precisa estar associada à instauração da mutualidade de cuidado. É inegável o fato de que para um profissional capacitar-se ao efetivo exercício de cuidado ao outro, é necessário que ele próprio também seja alvo de práticas de cuidado. Observou-se, nesse estudo, que o médico, ao buscar uma Residência, almeja a especialização e o aprimoramento técnico em determinada área da Medicina. Porém, ao ingressar na Residência, o profissional, muitas vezes recém formado, depara-se com um cenário marcado, frequentemente, pelo excesso e sobrecarga.

Diante das intensidades de vivências relativas à Residência Médica e das especificidades das práticas no contexto de urgência e emergência, as quais demandam prontidão e presteza no atendimento ao outro, corre-se o risco de o médico, em seu fazer, exercer um cuidado meramente tecnicista marcado pela indiferença ao outro e a si mesmo. Em oposição ao risco da indiferença, destaca-se a necessária sensibilidade à afetação do profissional, de forma que Ihe seja possível enlaçar competência técnica e sensibilidade. As Asserções construídas neste estudo reforçam a importância de um permanente exercício reflexivo sobre o processo de formação médica. Considera-se, ainda, que o aceite dos entrevistados em participar desse estudo desvela o valor atribuído por eles ao exercício reflexivo sobre suas práticas, já que todos denotaram importante capacidade crítica acerca de impasses presentes em seu fazer profissional.

Os dados obtidos indicam a importância de que se estabeleçam, no contexto institucional, espaços que visem estimular e fomentar permanentemente a capacidade crítica, reflexiva e proposições éticas relativas ao cotidiano profissional. Percebeu-se, também, como a sobrecarga e a experiência de desamparo decorrente da insuficiência de funções a serem desenvolvidas pelo preceptor acabam por prejudicar a motivação inicial de buscar a Residência Médica como espaço de aprimoramento da qualificação profissional. Trata-se, portan-
Davisson Gonçalves Giaretta e Mônica Medeiros Kother Macedo

to, de evidenciar a implicação institucional dessas situações denunciadas pelos participantes.

Ressalta-se a escassez de estudos qualitativos acerca de impasses e de dificuldades que se apresentam na prática médica, considerando a evidente intensidade de demandas à figura do médico, independentemente do contexto de atuação. Logo, salienta-se a importância e o valor do conhecimento decorrente de pesquisas qualitativas, visto que essa modalidade de investigação evidencia a experiência e a narrativa do sujeito, possibilitando o acesso e o aprofundamento de novos e singulares significados a respeito dos fenômenos estudados.

\section{CONTRIBUIÇÃO DE CADA AUTOR}

Certificamos que todos os autores participaram suficientemente do trabalho para tornar pública sua responsabilidade pelo conteúdo. A contribuição de cada autor pode ser atribuída como se segue:

D.G.G. e M.M.K.M. contribuíram para a conceitualização, metodologia e redação do manuscrito. D.G.G. realizou a investigação. M.M.K.M. foi responsável pela supervisão do trabalho metodológico com os dados coletados e redação (revisão) do artigo.

\section{DECLARAÇÃO DE CONFLITO DE INTERESSES}

Os autores declaram não haver conflito de interesse neste artigo.

\section{DECLARAÇÃO DE FINANCIAMENTO}

A pesquisa cujos dados constam como ilustrações no manuscrito foi financiada pela Bolsa de Produtividade em Pesquisa da segunda autora (PQ2015/ CNPq, Processo 306236/2015-0).

\section{REFERÊNCIAS}

Abdulghani, H. M., Al-Harbi, M. M. \& Irshad, M. (2015). Stress and its association with working efficiency of junior doctors during three postgraduate residency training programs. Neuropsychiatric Disease and Treatment, 11, 30233029. DOI 10.2147/NDT.S92408

Aredes, J. S. \& Modesto, A. L. (2016). Entre vidas e mortes, entre máscaras e fugas: um estudo sobre a prática médica hospitalar. Physis: Revista de Saúde Coletiva, 26(2), 435-453. http://dx.doi.org/10.1590/S0103-73312016000200006 


\section{W NTERAC̄̃OEM ET PSICOLOGIA}

Çalişkan Tür, F., Toker, I., Şaşmaz, C. T., Hacar, S. \& Türe, B. (2016). Occupational stress experienced by residents and faculty psysicians on night shifts. Scandinavian Journal of Trauma, Resuscitation and Emergency Medicine, 24(34), 1-8. DOI 10.1186/s13049-016-0225-4

Decreto $n^{\circ} 80.281$, de 05 setembro de 1977. (1977, 05 setembro). Regulamenta a Residência Médica, cria a Comissão Nacional de Residência Médica e dá outras providências. Presidência da República. http://www.planalto.gov.br/ccivil_03/decreto/1970-1979/D80281.htm

Erickson, F. (1997). Metodos cualitativos de investigación sobre la enseñanza. In M. Wittrock (Org.). La investigación de la enseñanza (pp. 195-301). Paidós.

Fagundes Netto, M. V. R., \& Kernkraut, A. M. (2019). Contribuições da psicanálise à medicina: grupo com residentes em um programa de cancerologia clínica. Rev. SBPH, 22(spe), 133-156.

Goulart, B. N. G., \& Chiari, B. B. (2010). Humanização das práticas do profissional de saúde - contribuições para reflexão. Ciência \& Saúde Coletiva, 15(1), 255-268. http:// dx.doi.org/10.1590/S1413-81232010000100031

HumanizaSUS. (2004). Política Nacional de Humanização: a humanização como eixo norteador das práticas de atenção e gestão em todas as instâncias do SUS. Ministério da Saúde. http://bvsms.saude.gov.br/bvs/publicacoes/humanizasus_2004.pdf

Ilić, I. M., Arandjelović, M. Ž., Jovanović, J. M., \& Nešić, M. M. (2017). Relationships of work-related psychosocial risks, stress, individual factors and burnout - Questionnaire survey among emergency physicians and nurses. Medycyna Pracy, 68(2), 167-178. https://doi.org/10.13075/ mp.5893.00516

Kude, V. M. M. (1997). Como se faz análise de dados na pesquisa qualitativa. Revista Psico, 28(2), 183-202.

Lei $n^{0}$ 6.932, de 07 de julho de 1981. (1981, 07 julho). Dispõe sobre as atividades do médico residente e dá outras providências. Brasil. http://www2.camara.leg.br/legin/fed/ lei/1980-1987/lei-6932-7-julho-1981-357276-normaatualizada-pl.pdf

Marques, R. C., Martin s Filho, E. D., Paula, G. S., \& Santos, R. R. (2012). Assédio moral nas residências médica e não médica de um hospital de ensino. Revista Brasileira de Educação Médica, 36(3), 401-406. http://dx.doi.org/10.1590/S010055022012000500015

Martins, L. A. N. (2010). Residência Médica: estresse e crescimento. Casa do Psicólogo.

Miranda, K. L., Serafıni, P. C. \& Baracat, E. C. (2012). O cuidado psicológico ao médico em reprodução assistida: um enquadre diferenciado. Estudos de Psicologia (Campinas), 29(1), 71-79. http://dx.doi.org/10.1590/S0103166X2012000100008.
Davisson Gonçalves Giaretta e Mônica Medeiros Kother Macedo

Moretto, M. L. T. (2019). Abordagem psicanalítica do sofrimento nas instituições de saúde. Zagodoni.

Pereira Jr., G. A., Fraga, G. P., Aranud, F., Gula, E. A., Slullitel, A. \& Garcia, V. L. (2015). $O$ ensino de urgência e emergência de acordo com as novas Diretrizes Curriculares Nacionais e a lei do Mais Médicos. Cadernos ABEM, 11, 20-47.

Portaria GM/MS n² 2.048, de 05 de novembro de 2002. (2002, 05 novembro). Ministério da Saúde. https://bvsms.saude. gov.br/bvs/saudelegis/gm/2002/prt2048_05_11_2002. html

Purim, K. S. M., Borges, L. M. C. \& Possebom, A. C. (2016). Perfil do médico recém-formado no sul do Brasil e sua inserção profissional. Revista do Colégio Brasileiro de Cirurgiões, 43(4), 295-300. http://dx.doi.org/10.1590/010069912016004006

Resolução $n^{\circ}$ 02/2006, de 17 de maio de 2006. (2006, 17 maio). Dispõe sobre os requisitos mínimos dos Programas de Residência Médica e dá outras providências. Conselho Nacional de Residência Médica (CNRM). http://portal. mec.gov.br/dmdocuments/resolucao02_2006.pdf

Resolução $n^{\circ}$ 03/2014, de 20 de junho de 2014. (2014, 20 junho). Institui as Diretrizes Curriculares Nacionais do Curso de Graduação em Medicina e dá outras providências. Ministério da Educação. http://www.fmb.unesp.br/Home/ Graduacao/resolucao-dcn-2014.pdf

Resolução $n^{\circ}$ 2.077/14. (2014). Dispõe sobre a normatização do funcionamento dos Serviços Hospitalares e Urgência e Emergência, bem como do dimensionamento da equipe médica e do sistema de trabalho. Conselho Federal de Medicina (CFM). http://www.rio.rj.gov.br/dlstatic/10112/5125745/4209118/ RESOLUCAOCFMn2.07714.pdf

Resolução $n^{\circ}$ 2.149/2016. (2016). Homologa a Portaria CME $n^{\circ}$ 02/2016, que aprova a relação de especialidades e áreas de atuação médicas aprovadas pela Comissão Mista de Especialidades. Conselho Federal de Medicina (CFM). http://www.portalmedico.org.br/resolucoes/ cfm/2016/2149_2016.pdf

Rios, I. C. (2009). Caminhos da humanização na saúde: prática e reflexão. Áurea Editora. http://pessoacomdeficiencia. sp.gov.br/usr/share/documents/CAMINHOS_DA_HUMANIZACAO_NA_SAUDE.pdf

Rios, I. C. (2016). The contemporary culture in medical school and its influence on training doctors in ethics and humanistic attitude to the clinical practice. International Journal of Ethics Education, 1, 173-182. DOI 10.1007/ s40889-016-0012-0

Roberts, L. W., \& Kim, J. P. (2015). Informal health care practices of residents: "curbside" consultation and self-diagnosis and treatment. Acad. Psychiatry, 39(1), 22-30. https:// doi.org/10.1007/s40596-014-0170-3 


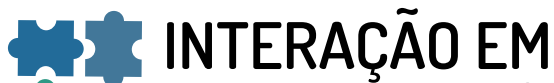 E. PSICOLOGIA}

Rosado, I. V. M., Russo, G. H. A. \& Maia, E. M. C. (2015). Produzir saúde suscita adoecimento? As contradições do trabalho em hospitais públicos de urgência e emergência. Ciência \& Saúde Coletiva, 20(10), 3021-3032. http://dx.doi. org/10.1590/1413-812320152010.13202014.

Sant'Ana, E. R. R. B. \& Pereira, E. R. S. (2016). Preceptoria médica em serviço de emergência e urgência hospitalar na perspectiva de médicos. Revista Brasileira de Educação Médica, 40(2), 204-215. http://dx.doi.org/10.1590/ 1981-52712015v40n2e00542014
Turato, E. R. (2011). Tratado da metodologia da pesquisa clínico-qualitativa: construção teórico-epistemológica, discussão comparada e aplicação nas áreas da saúde e humanas (5 $5^{\mathrm{a}}$ ed.). Vozes.

Volz, N. B., Fringer, R., Walters, B. \& Kowalenko, T. (2017). Prevalence of horizontal violence among emergency attending physicians, residents, and physician assistants. Western Journal of Emergency Medicine, 18(2), 213-218. DOI: 10.5811/westjem.2016.10.31385

Data de submissão: 17/01/2020 Primeira decisão editorial: 06/07/2020 Aceite: $10 / 08 / 2020$ 